\title{
RESEÑA: AFTER THEORY. TERRY EAGLETON
}

\author{
JOSÉ FRANCISCO FERNÁNDEZ SÁNCHEZ \\ Universidad de Almería
}

\section{Eagleton, Terry. 2003. After Theory. New York: Basic Books. 231 páginas. ISBN: 0-465-01773-8.}

El último libro de Terry Eagleton, After Theory, comienza ofreciendo una panorámica del estado actual de la teoría cultural (o simplemente "theory") y acaba siendo un tratado de moral práctica. No hay una intención despectiva en este planteamiento; es sólo una forma de ilustrar el sesgo que ha tomado la obra de este influyente pensador inglés, interesado actualmente en trascender el mero análisis literario para influir en parcelas relacionadas con la conciencia personal y, de una forma consecuente, en la vida pública.

La causa que mueve a Eagleton a escribir este ensayo hay que buscarla en la extrema banalidad en la que han caído los estudios culturales en los últimos años. La teoría cultural, afirma el autor, se ha despojado del sentido crítico y se esfuerza en perseguir cuestiones espurias. En un comienzo brillante por su ingenio Eagleton lanza una mirada mordaz al objeto de su análisis: "Quietly-spoken middle-class students huddle diligently in libraries, at work on sensationalist subjects like vampirism and eye-gouging, cyborgs and porno movies" (2-3); "In the old days, rock music was a distraction from your studies; now it may well be what you are studying" (3).

$\mathrm{Su}$ punto de partida es que los grandes autores que revolucionaron el pensamiento contemporáneo, dando lugar a una edad de oro de la teoría cultural entre 1965 y 1980 (Lacan, Barthes, Foucault, Derrida, Kristeva...) bien han desaparecido, o bien, con toda probabilidad, han escrito sus obras de mayor impacto. Los pensadores que han seguido sus huellas no han conseguido alcanzar las cotas de originalidad de estas figuras de primer orden. La teoría sigue siendo necesaria como guía para entender el conocimiento y es un engaño pensar que no necesitamos una reflexión que canalice y dé fundamento a la vida intelectual: "La hostilidad a lo teórico (...)" escribía Eagleton en Una introducción a la teoría literaria "equivale a una oposición hacia las teorías de los demás y al olvido de las propias" (1988: 10). Es imposible por consiguiente volver atrás a una época de inocencia textual que, por otra parte, nunca existió. Lo que tenemos ahora es para Eagleton una imitación de obras pioneras en este campo y un progresivo alejamiento de todo compromiso ético. En los ocho capítulos de los que consta el volumen Eagleton propone, básica- 
mente, trazar el origen y la evolución de la teoría cultural (capítulos 1-3), analizar sus deficiencias y valorar sus aciertos (capítulo 4), y volver a situarla en unos cauces de sentido común y de pleno significado en el mundo en que vivimos (capítulos 5-8).

La crítica de Eagleton a lo que se ha convertido en la forma dominante del pensamiento contemporáneo y que conocemos con el nombre de posmodernismo no es algo nuevo. En su libro de 1996 Las ilusiones del posmodernismo ya se encontraban de manera más sucinta ideas que desarrollaría posteriormente en After Theory. En el primer libro apuntaba, por ejemplo, que el pensamiento posmoderno deja de lado cuestiones fundamentales para el ser humano, como la naturaleza, las clases sociales o la biología (1997: 51). Desvelaba asimismo las contradicciones de una corriente teórica que se siente insultada por las opiniones dogmáticas cuando pontifica con la misma autoridad: “[El posmodernismo] Está pleno de prescripciones morales universales — la hibridez es preferible a la pureza; la pluralidad a la singularidad; la diferencia a la autoidentidad - y denuncia ese universalismo como un opresivo peso del Iluminismo" (Ibid., 54). Al igual que afirma ahora en After Theory, en Las ilusiones del posmodernismo reconocía como méritos el hecho de que esta tendencia ha contribuido notablemente a que importantes cuestiones como la sexualidad, el género o lo étnico formen parte del debate político hoy en día (1997: 45).

También en otros libros anteriores Eagleton delineaba trazos argumentales que retomaría más tarde. En La idea de la cultura (2000) explicaba cómo desde los años 60 los estudios de literatura se han transformado en política cultural; cómo, siguiendo un ejemplo del autor, los estudiosos han dejado el drama Tudor para analizar los tebeos. En este libro ya hablaba de la "inflación de la cultura" (2001: 67), y advertía de los peligros que entraña la falta de rigor a la hora de entender el concepto de cultura y sus posibles acepciones: "Cuando se espera demasiado de ella, cuando se le exige que sea un sustituto pobre de Dios, de la metafísica o de la política revolucionaria, puede empezar a manifestar síntomas patológicos" (Ibid.). Lo que hace Eagleton, por tanto, en su nueva publicación es reforzar ideas ya esbozadas y exponerlas de forma más sistemática y con mayor agudeza intelectual.

En lo que hemos considerado como la primera parte del libro, los tres primeros capítulos en los que sigue el desarrollo de la teoría cultural hasta nuestros días, Eagleton deja patente que el enemigo a combatir no es el posmodernismo en sí, sino el capitalismo, un sistema con el cual esta corriente cultural coquetea sin ambigüedades y al que Eagleton define como "... an impeccably inclusive creed: it really doesn't care who it exploits" (19). Frente al sistema capitalista, en opinión de Eagleton, el socialismo sigue teniendo validez tanto para diseccionar y exponer los abusos de un régimen alienante como para erradicar las injusticias que han dado lugar a la crisis global de comienzos de milenio: "For a socialist, the true scandal of the present world is that almost everyone in it is banished to the margins" (19). Eagleton realiza un moderado ejercicio de autocrítica cuando opina que en Occidente, a partir de los años sesenta, la izquierda tradicional (o el marxismo para utilizar un término genérico) pasó a ocupar posiciones en el mundo cultural a causa de su impotencia y desencanto en la esfera política (31). En la misma línea mantiene que el consumismo desmedido y la afluencia material han dejado al marxismo aturdido, bloqueado, y sugiere que quizá no estaba preparado para lo virtual y el dominio de la imagen 
y de los medios que caracteriza al capitalismo en su fase actual (38). Eagleton parece coincidir en líneas generales con el análisis sobre el pasado y el futuro del socialismo que han hecho otros intelectuales como Alan Sinfield. Al contrario que éste, Eagleton no sugiere propuestas concretas de actuación para la izquierda militante, ni quizá su autocrítica sea tan descarnada, pero mantiene en prácticamente los mismos términos su defensa del socialismo como alternativa: “...because it [Socialism] remains, as it always was, the response which capitalism, through its own contradictions, provokes" (Sinfield 1997: xx).

En el cuarto capítulo, titulado "Losses and Gains", Eagleton reconoce, entre otros méritos, que gracias a los estudios de teoría se han establecido firmes conexiones entre la cultura y el poder, y se ha demostrado que no hay formas culturales políticamente inocentes. El balance general, no obstante, es negativo para esta tendencia debido a su ensimismamiento. El autor afirma con rotundidad que la teoría cultural ha sido "...reticent about death and suffering, dogmatic about essences, universals and foundations, and superficial about truth, objectivity and disinterestedness" (101-102). A partir de este punto Eagleton iniciará su tarea de poner la teoría al servicio de los temas cruciales para el ser humano, y comenzará con una rehabilitación de conceptos que el posmodernismo ha desprovisto de significado. La idea de verdad, rechazada por muchos por considerar que esconde posturas autoritarias, será el primer término que Eagleton ponga en su contexto adecuado. Para el autor, la verdad no tiene nada que ver con el fanatismo y, contrariamente a lo que piensa el relativismo posmoderno, afirma que si algo es verdad no hay posibles ambigüedades, lo que en algunas circunstancias es algo más que una simple cuestión semántica: "If it is true that a situation is racist, then it is absolutely true. It is not just my opinión, or yours" (106). Otro concepto denostado por la teoría cultural, el de objetividad, lo sitúa el autor en relación con la felicidad y con la realización plena del potencial del ser humano. Para Eagleton el desarrollo personal no es un hecho subjetivo y opina que la objetividad es necesaria para conseguir una sociedad más justa: "To try to see the other's situation as it really is is an essential condition of caring for them" (131).

Eagleton dedica un capítulo entero, el sexto, a rehabilitar el concepto más enmarañado de prejuicios y de falsas prohibiciones de todos, como es el de la moral. Frente a la versión puritana y pacata de moral, el autor cree que se trata en realidad de una idea basada en la alegría y en el disfrute de la vida. El verdadero sentido de códigos y normas, afirma, debe ser para proteger la vida, y especialmente los derechos de los más desprotegidos: "Love is a notoriously obscure, complicated affair, and moral language is a way of trying to get what counts as love into sharper focus" (146).

En los dos últimos capítulos Eagleton hace precisamente eso, enfocar con más exactitud el objeto de su crítica y aquí su estilo se desprende de gran parte de su característica fina ironía para impregnarse de indignación ante acontecimientos de magnitud global. La ceguera de los mandatarios de la Casa Blanca, la naturaleza del fundamentalismo o las víctimas del poder desmedido son los temas que ocupan estas páginas. Su tesis fundamental al criticar la mentalidad norteamericana se dirige a su esencia, al culto del éxito y a su negativa a admitir el fracaso. Para Eagleton la vida humana es limitada, provisional, frágil (de ahí que la teoría cultural deba reconducirse hacia los temas que hasta ahora ha despreciado como la enfermedad o la muerte), y ante el pensamiento triunfalista propone una 
cura de humildad: "To accept death would be to live more abundantly (...) if we really could keep death in mind, we would almost certainly behave a good deal more virtuously than we do" (210).

El libro finaliza con un epílogo demoledor en el que, sin nombrarla, se intuye de fondo la guerra de Irak. Eagleton no escatima términos tajantes cuando menciona aquí a George W. Bush ("a fraudulently elected president"), Guantánamo ("their Cuban concentration camp") o el papel del propio país del autor en el conflicto ("an off-shore US aircraft carrier once known as the United Kingdom"). Su propuesta de basar la idea del ser humano no en sus impulsos de grandeza sino en su fragilidad y en sus limitaciones cobra en este contexto una inmediata relevancia.

\section{REFERENCIAS BIBLIOGRÁFICAS}

EAGLETON, T. 1988 (1983). Una introducción a la teoría literaria. Trad. de José Esteban Calderón. México: Fondo de Cultura Económica.

. 1997 (1996). Las ilusiones del posmodernismo. Trad. de Marcos Mayer. Buenos Aires: Paidós.

. 2001 (2000). La idea de cultura. Trad. de Ramón José del Castillo. Barcelona: Paidós.

Sinfield, A. 1997. Literature Politics and Culture in Postwar Britain. London: The Athlone Press. 